\title{
Transformation of the Model of Science and Higher Education Interaction in Yakutia
}

\author{
Abramova Mariya Alekseevna \\ Department of ethno-social research, Institute of philosophy and law SB RAS \\ Russia, Novosibirsk, Email:marika24@yandex.ru \\ Krasheninnikov Valery Vasilyevich
}

Professor of Novosibirsk state pedagogical University; Email: vkrash48@mail.ru

\section{Doi:10.5901/mjss.2016.v7n6p165}

\section{Abstract}

The article is devoted to the research of the dynamics of development of science and education interaction as social institutes in the conditions of the Soviet and Post-Soviet Russia. The Yakut scientific center of the Siberian department of the Russian Academy of Sciences and Northeast federal university were chosen as the objects for the analysis of history of formation and transformation of the interaction model. The subject of the Russian Federation where the development of these establishments was performed has its own national and regional specifics. In the article the method of historical analysis is used. It is shown that the success of implementation of innovative projects in modern Russia in the field of higher education is directly connected to the background of the long-lasting cooperation of the Russian Academy of Sciences with the universities. Thus, the efficiency of the usage of the Anglo-Saxon model of science and education interaction in the conditions of modern Russia is practically based on the completeness of the realization during the Soviet period of scientific and educational establishments within the Prussian (Austro-Russian) model, what confirms the immense efficiency of the last one. The work was performed under the grant of the Russian humanitarian scientific Fund (project No. 15-03-00194a).

Keywords: model, interaction of science and education, higher education, federal university, Yakutia.

\section{Introduction}

Historical practice of science and education interaction, characteristic for the Prussian (Austro-Russian) educational system where the scientific and educational establishments coexist independently, was supported by the realization of the concept of teaching within a didactic encyclopedic learning. This approach created favorable conditions for the development of the fundamental science. When applying the concept of a didactic utilitarianism, that is characteristic for the Anglo-Saxon educational system focused on the development of action-oriented scientific and educational aspects, the gradual merge of scientific and educational institutions is unavoidable.

In modern Russia, as well as in many European countries, gradual refusal from implementation of the didactic encyclopedic learning concept and switching to the usage of a didactic utilitarianism model is observed. First of all, it may be seen in the change of science and education interaction models.

The analysis of the results of federal and national research universities of Eastern and Western Siberia, allowed to draw a conclusion that the most effective realization of the science + education model on the basis of higher vocational colleges in Russia happens only in case if the university already had a long-lasting background of cooperation with establishments of the Russian Academy of Sciences. Those are The Moscow State and the Novosibirsk State (that got the status of a research university) Universities that entered the list of Top-200 of a rating QS World University Rankings.

The Northeast University created on the basis of the Yakut state university of M. K. Ammosov and having long history of development under the influence of the Siberian Branch of the Russian Academy of Sciences, same as the MSU and the NSU is one of the few universities that received the federal status.

In this article we want to track the transformation of science and education interaction model in Russia based on the example of forming of this university.

\section{Research Objectives}

1- Comparison based on the historiographic analysis of the main stages in development of the system of higher 
education and science in Yakutia.

2- Representation of dynamics of transformation of the science and education interaction models as social institutes in the conditions of the Soviet and Post-Soviet Russia.

\section{Research Methodology}

The main scientific approach which is realized in this article is the sociocultural approach understood by us within P. Sorokin (2000) concept as the unity of a triad "the personality - culture - society". The leading principles of the research are: systematics, complexity and interdisciplinary. In this context the development of practice of interaction in separately taken region of Russia - the Republic of Sakha (Yakutia), the research chosen by us as base, is considered together with global tendencies which have transformed an education system in the world in general and in Russia in particular.

The factors determining interaction of science and education are presented by specifics of historical and cultural development and socio-political conditions of forming the region as component of Russia. The chosen aspect assumes the use of methods of the retrospective analysis, historiographic analysis of literature and archival sources, and also the analysis of the statistical data provided by the state committee on statistics of the Republic of Sakha (Yakutia).

The technique of a research includes collecting, handling and the analysis of information: 1) about historical and cultural prerequisites of forming the educational system and the development of scientific institutions in Russia in general and in the republic in particular; 2) about the objective and subjective factors exerting a positive and negative impact on interaction of science and education, 3) about possible scripts of the development of interaction in the conditions of transformation in Russia.

Russian, exactly Germanic-Russian (Prussian, Austrian) system of education traditionally emphasises teaching as one of factors of socializing the individual, supposing that it has the task of broadcasting the cultural models. The fundamental nature of education that became the distinctive feature of the Prussian system was based on the concept of the didactic learning that was supported by Ya.A. Komensky (Sadler, 1966), J. Milton (Parker, 1962). The representatives of the stream believed that the student's mastering of the immense amount of scientific knowledge will allow to form the foundation for the further conscious choice of his living position. Also it was supposed that the ability of making a conscious choice is formed not only in the process of the individual's growing-up, but also depending on the volume of the acquired information. Thus, the degree of the student's achieving of the purposes and goals of education was defined, first of all, by the volume, consistency of the acquired knowledge, and also the ability to analyze, increased attention to the humanitarian training of specialists. While the student was accumulating the information, the nature of educational activity was also changing - the number of the practical classes and tasks aimed at analytical work increased. But the strategy of presenting educational material from the general to the particular (deductive principle) didn't change (Abramova, Krasheninnikov, Liberska, Farnika, 2015).

The changes in the society that caused the enormous growth of volume of information in the XX century, revision of management styles not only at the level of the states but also in educational process, experimental works of psychologists, on detecting the regularities of the personality development put the efficiency of the concept of a didactic encyklopedizm into doubt. But owing to historical events in the USSR, and also in many countries of Eastern Europe, realization of this concept at the level of the state educational policy in the XX century was extremely necessary as in the 20-30th the issue of elimination of illiteracy of the population was being solved. That's why, before the revision of an educational paradigm became acute, it was necessary that the countries could save a certain educational potential.

In the second half of the XX century, along with the changes in politics and science, the system of education again becomes the stage where the disputes on the efficiency of various approaches develop: didactic encyclopedic learning, formalism and utilitarianism.

The pragmatic approach, on which the accent in an Anglo-Saxon (American) education system is traditionally put, is actually the basis of the didactic utilitarianism concept that appeared at a turn of XIX and XX centuries in the USA. The concept of practical activities (training) lies in the basis of the Anglo-Saxon educational model. The representatives of this stream (J. Dewey (Bernstein, 1966), G. Kershenshteyner (Kelly, 2004:94-5.) understand teaching as a continuous process of transformation and enrichment of the student's life experience. So the characteristic features of the AngloSaxon educational system are: leaning on an empirical experience, special attention to assimilation of information in the field of science and technical disciplines, spending more time practicing and writing works with the subsequent working off of the contents with the tutor. The main strategy of planning the educational process is from details to the general (the principle of induction).

Quality of the received education is determined, first of all, by the formed skills and abilities of solving the applied tasks. That's why the connections between the contents of the education of particular disciplines are built by means of 
their realization through individual and public work of the student. The only way to master social heritage in the AngloSaxon educational system is connected with the opportunities of the student's inclusion into those kinds of activities which allowed a civilization to become what it is now. So, the contents of the educational cycle has to be fully optimized what does not always suggest following the principle of sequence and continuity in studying of the subjects. The value of educational process is not the degree of the structure of thinking and analytical opportunities, but freedom of the student while forming his experience. As a result, the didactic utilitarianism concept assumes not the expansion of ideas of the existed and existing cultural models, but the reconstruction of a social experience only as a base for its development. Subsequently education carries out the developing function through the activity limited by solving only the narrow pragmatic problems (Abramova, Krasheninnikov, Liberska, Farnika, 2015).

Thus, considering the levels providing the individual's enculturation - cultural, personal and technological - we can notice essential differences of the Germanic-Russian and Anglo-Saxon educational systems. If in the first one orientation on the fundamental nature provides at all levels, first of all, acquaintance with various cultural models which aren't surely realized in the country where the teaching being performed, while the second one is concentrated only on reproducing of its own model by means of granting a choice and, as a result, responsibility for it to the student, who is solving the problems through learning.

The unique character of the modern situation in educational paradigms development suggests that if the drawbacks of the Anglo-Saxon educational model which are expressed in the narrow pragmatic aiming of the authors of educational process at solving the specific applied objectives are solved due to the humanitarization of education and expansion of ideas of experience of others, then in the Germanic-Russian educational model, on the contrary, there is a withdrawal from the principle of fundamental nature to the pragmatic orientation.

Signing of the Bologna declaration became in this context the catalyst of the process. For most universities based on a Prussian (Austrian) educational system not simply the revision of the existing requirements to the educational system within the country, but actually the change of the educational system model itself turns out to be the consequence of aiming to become the equal participant in the international educational space (Zagvyazinsky, 2005). But whether these tendencies of revision of an educational paradigm will become for the countries a way to increase the efficiency of educational process or a destruction of traditions and a loss of the achievements, time will show. We can only note that within Russia this transition caused breaking of the communications between the academic science establishments and education as the attempt to connect them actually led to discrediting of the achievements of the previous eras. Let's have a closer look at it on the example of the historiographic analysis of the main stages of development of the system of higher education and science in Yakutia.

\section{The Results and Discussion}

The history of forming of the educational system in Yakutia can conditionally be divided into 3 stages: till 1917, Soviet, Post-Soviet.

\subsection{The first stage. The formation of prerequisites of the creation of the educational system in Yakutia till 1917}

For the first stage of forming an education system, vigorous missionary activity of orthodox church and educational activity of political exiled are characteristic. The conditions for introducing the educational activity in Yakut peoples' languages were put what lately became a basis for initiation of a question of creating the textbooks and programs for teaching children on their native Evenkskiya, Evenki, Chukchi, and Yukaghir languages. One of the most important factors of strengthening the secular nature of education became the urge to research and prevent the culture of Yakut people (Abramova, 2003), so was the growth of interest in carrying out scientific researches of the Northern Russia that predetermined not only the appearance of the Yakut department of the Russian geographical society, but also the formation tendencies of higher education in Yakutia in the future.

By 1917, despite all the efforts on educating the folks living in the north of Russia only $2 \%$ of the population in Yakutia were literate, including Russians, and among the native folks - only 0,7\% (Torgovkina, 2001, 59). The most serious reason of the current situation was that the most part $(91,1 \%)$ of schools was limited by the educational program in one class, and opportunities for continuation of studying in educational establishments of the next level were few. The only university close to Yakutsk was the one opened in Siberia in Tomsk in 1888. - There were a lot of opponents for creating a university in Siberea - a place of "exile and penal servitude". (Zakharova, 2004, 8).

The lack of financing, motivation of the population to the opening of schools in the rural remote places, and also the opportunities of replenishment of personnel structure of the teachers caused opening of schools mainly in the cities 
(according to 1911 only in Yakutsk there were 18 schools).

Results of the first stage: Creation of prerequisites for the formation of secular educational system.

4.2 The second stage. Formation of the educational system and models of interaction between university and institutions of science during the Soviet period in Yakutia

The second stage of developing the educational system was marked by the fact that after October revolution the Cultural Revolution was started by the government of the Soviet Russia - the policy of involving the citizens into the constructing of socialism owing to what vigorous fight for elimination of illiteracy and increasing of educational level including the Northern folks began. These decisions corresponded to the idea of helping the folks to overcome the primitive-communal system and were supported by practice of realization of the measures showing the paternalistic relation from the state.

So, the famous Yakut linguist S. A. Novgorodov in 1917 made the Latinized Yakut alphabet and published the first Yakut abc-book of "Suruk-bichik" together with V. M. Ionov, and the Russian government helped to cast the Yakut font in Moscow, provided the typographical equipment and paper, and in 1921 the first book for reading in the Yakut language was printed. After the delivery of a font to Yakutia the Kyym newspaper ("Spark") and the Cholbon magazine ("A morning star") began to appear in the Yakut language in 1923.

On November 21, 1921 "The provision on universities of RSFSR" according to which training at the higher school became free for the proletarian and poor people was approved. They had to be admitted to educational institutions freely and be getting a grant. For the representatives of the Northern folks special preferential places were allocated.

In 1922 the resolution "About introducing of the Yakut language in all schools of the republic" was approved by the Council of People's Commissars of YaASSR (Kalashnikov, 2002, 47). Within YaASSR the Yakut language became common in the official relations and in office-work on an equal basis with Russian.

In 1926 the comprehensive program of teaching children at the Yakut rural school of the first step where they could receive along with general education knowledge some professional specialties - as teachers, accountants, agronomists was accepted (Pesterev, 2005, 57).

Gradually the process of opening the educational institutions in Yakutsk amplified. In 1925 the agricultural technical school was opened, in 1926 the national military school was opened. In 1930 in Aldan a Mountain technical school was opened. In the same year in Yakutsk technical schools were opened: consumer cooperation, economic and finance and road-building ones. The teachers were taught by the Yakut, Vilyuysky, Churapchinsky pre technical schools, Irkutsk teacher's college and other colleges of the country.

From 1931/1932 academic years, general compulsory elementary education for children of 8 - 10 years and overages, and also seven years' compulsory education were accepted.

By 1939 the rate of elimination of illiteracy in Yakutia reached the level of 80,5\% from all the population of $9-49$ years (including 86,8\% - among men, 72,6\% - among women). Besides, the process was successful both in the cities, and in the rural areas.

The measures for eliminating illiteracy took place along with the amplifying interest of the Soviet government in exploring the natural treasures of Yakutia.

On April 25, 1924 M. K. Ammosov on behalf of the Yakut the Autonomous Soviet Socialist Republic government appealed to the Academy of Sciences of the USSR to organize a research expedition to study the natural-productive forces of the republic (Ammosov, 1967, 251-252). Having considered the request of the Yakut Government, the presidium of the Academy of Sciences of the USSR created the special commission for studying Yakutia in 1925 which worked for 10 years and laid the foundation to systematic complex studying of productive forces of certain regions of the country by the Academy.

On May 17, 1933 in Yakutia the department of All-Union Arctic institute was opened to carry out the management of the research work on comprehensive study of polar and sub polar areas of the republic. So, carrying out scientific research in Yakutia, the results of the first complex expedition, and also the lack of its own establishment which could perform an educational function as well as to participate in organizing the research work in the republic caused the relevance of solving the question of creating a scientific institutions network on its territory. Combined with the results of measures on training of the top skilled professionals and active introduction of the arrived first graduates to all the spheres of national economy of Yakutia it provided the basis for creating a higher educational institution in the republic. As a result in 1932 the workers' faculty was created, in 1934 the Yakut Pedagogical institute (PI)

Among the significant events which influenced the development of higher education in Yakutia was a strengthening of requirements of Narkompros to making the research work by teachers which was recorded in orders at the very beginning of war (National archive, 828). In teacher's college scientific conferences for the first time started being held, 
and this experience changed the perception of it as smithies only for teachers.

Perhaps, partially exactly the conferences in $\mathrm{PI}$, and also the renewal after a two-year break in 1943 of the work of the Yakut Research language literature and history of YaASSR (Yakutia) institute, and the two plenums which it held in 1943 and 1947 were the catalyst for the Council of ministers of the USSR to decide to open a research base of the Academy of Sciences of the USSR in Yakutia. Especially it would be desirable to note that among the scientists who in the future headed the Yakut branch $(\mathrm{YaB})$ of the Academy of Sciences of the USSR institutes there were teachers and graduates of PI what showed the successful realization of the principle of an obligatory combining of training and research activities.

Prompt expansion of research interests and discovery of a research base of the Academy of Sciences of the USSR in Yakutsk caused the growth of the need for the highly qualified personnel. For this reason, in 1948 the first postgraduate study in Yakutia at $\mathrm{YaB}$ of the Academy of Sciences of the USSR was opened. From this point the preparation of their own scientists officially begins.

The preparatory work on creating the university in Yakut ASSR was conducted by the Autonomous Soviet Socialist Republic since 1945. As a result on August 23, 1956 a Resolution of Council of ministers of the USSR on creation on the basis of PI of the Yakut State University (YSU) appeared.

The development of the university went along with the structural changes in $\mathrm{YaB}$ of the Academy of Sciences of the USSR. In 1957 the branch was included into the structure of the Siberian department of Academy of Sciences of the USSR. (Torgovkina, 2001, 202). The development of YaB from the Academy of Sciences of the USSR perceiving the Yakutsk State University (YaSU) as a basic university to prepare the scientists caused the revision of the names of the faculties by the university and the specification of specialties on which students were trained.

According to census of 1970 , the republic took the third place by the number of people with the higher and average (full and incomplete) education on 1000 people (at the age of ten years and older), and on 1000 working - the sixth place among the16 autonomous republics that were a part of RSFSR (Torgovkina 2001, 65).

The Yakut branch of the Academy of Sciences of the USSR turned into the large scientific center in the northeast of the country attracting not only the Soviet scientists, but also foreign ones with the opportunities for carrying out scientific researches. Within the educational process at the higher school it caused the increase of requirements to the level of training of the graduates.

Results of the second stage: 1) Formation of the educational system in Yakutia. 2) Creation of network of scientific institutions on the basis of the Yakut branch of the Siberian department of the Academy of Sciences of the USSR. 3) Forming of the interaction between university and the Yakut branch of the Siberian department of the Russian Academy of Sciences by the principle of basic educational institution.

\subsection{The third stage. Transformation of the model of interaction between university and scientific institutions in Yakutia during the Post-Soviet period}

The third stage in developing the system of the higher education is connected with political, social and economical reorganization which started being carried out in the 80th in the USSR, and lead to some destabilization in society, in science and education. This period, considering national and regional specifics of YaASSR we will divide into two stages: aspiration to sovereignty and federalization.

The first half of this stage is connected with strengthening of separatist sentiments in the republic. On the tendencies of revising the social values that were characteristic for the whole Russia the aspiration to sovereignty process, which starts gaining strength already in the late 80th, leaves its mark in the republic.

The Yakut branch of the Siberian office of Academy of Sciences of the USSR in 1988 becomes the Yakut scientific center (YaSC) of the Siberian Branch of the Russian Academy of Science.

By the president of the Republic of Sakha (RS) (Yakutia) M. E. Nikolaev's decree on February 6, 1993 YaSU was given the status of the Head higher education institution of the Republic responsible for the organization and the quality of humanitarian, social and economic, pedagogical and natural-science training of specialists. In 1996 YaSU took the 4th place among 22 higher education institutions of Siberia and the Far East on the number of students. (Pesterev, 2005, 208).

Decree of the President of RS (Ya) in 1993 an Academy of Sciences of RS (Ya) as self-governed highest scientific institution of the Republic of Sakha (Yakutia) was created to unite the scientific capacity of the republic and to form the regional scientific policy.

As a result, one of the most important tendencies of interaction of science and higher education in Yakutia at a stage of aspiration to sovereignty became the weakening of connections, between the establishments of science and 
education while during the Soviet period they had interdependent character. The university as the head higher education institution of the republic had already required more autonomy when choosing a strategy of its development what found the reflection first of all in its organizational activity.

Opening of the borders in the 90th of the XX century by Russia, adoption of the Declaration on the sovereignty by the republic created the conditions for expansion of a network of the international contacts of the university. In 1996 in Yakutsk the constituent assembly of assembly and the first international conference of the Academy of the Northern forum took place. The republic becomes the coordinator of the "Circumpolar Culture of the Arctic and Northern Folks" program (Pesterev, 2005: 212).

By the beginning of the XXI century the main scientific potential was concentrated, as earlier in two communities: in Yakutsk scientific center of the Siberian Branch of the Russian Academy of Science and in the Yakutsk state university. But the reforms of the last decade of the XX century, strengthened attention to the preparation of the national professionals in YaSU (Abramova, Goncharova, Kostiuk, 2011), the influence of the multidirectional strategies of management of federal and republican organs on two largest organizations of science and education - substantially affected the nature of their cooperation, and also the processes happening within these structures.

So, the second part of the Post-Soviet period in educational system and science development in Yakutia was connected with the strengthening of moods on federalization. In the republic a problem of the higher school and fundamental science integration became acute.

To bring to life the idea of integration of science and education the available scientific and educational infrastructure was renewed and the new scientific and educational centers were created. Partially emergence of the opportunities for carrying out the scientific researches allowed returning to the public sector of the researchers who earlier had to leave for a business sector and non-state higher education institutions.

For the first four years the purpose of appearing of the federal university in Yakutia was transformed. Originally the mission of the university was signed as cultivation of competitive experts, performance of the researches and innovative and technological developments to form an economically steady socially developed subpolar region providing high quality of life, preservation and cultural development of the Northeast Russian folks. The YaGU became The North Eastern Federal University (NEVU). The latest data on the results of the activity of NEFU show that the university becomes a large regional center which claims not only to perform educational functions, but also to organize the scientific researches in Yakutia.

Results of the third stage: 1) Transformational processes of the Post-Soviet period in RS(Ya) have caused the change of roles of university and institutions of science in the created interaction model. 2) The Yakut state university (SVFU) receives the status of federal and begins to apply for performance of functions of the educational regional center, as well as scientific.

\section{Conclusion}

The presented historiographic analysis of the stages of development of the system of higher education and science in RS (Ya) shows that high productivity of realization of the federal university model as an example of merging of science and education couldn't take place without a long stage of cooperation, and actually joint development which united YaSC $(\mathrm{YaB})$ of the Siberian Branch of the Russian Academy of Science and NEVU (YaGU). So, we can be convinced on this example that the efficiency of using of an Anglo-Saxon model of interaction of science and education in the conditions of modern Russia is caused by completeness of realization during the Soviet period of scientific and educational establishments within Prussian (Austro-Russian) model. That confirms the efficiency of the last one.

It is also necessary to focus on the fact that dynamics of interaction of science and education that we considered within Yakutia is only one of the historic examples of developing in the USSR regions, and subsequently in Russia. And processes of creating of scientific structures within a university are characteristic not only for NEVU, but also for many universities. Only the results of performing these innovations remain quite predictable as each of universities realizing the concept "science + education" at the moment isn't something happening here and now, and has a long history of its forming what defines the success or the failure of these undertakings in the nearest future. We can assume that the strengthening of the universities that had a long background of cooperating with the Russian Academy of Sciences is only a logical continuation, and also a confirmation of the efficiency put during the Soviet period of the science and education system.

In this situation, of course, it is possible to assume that the Prussian (Austrian) educational system was less flexible in modern conditions, unlike the Anglo-Saxon, more sensitively reacting to the change of the market that is constantly demanding improvement of the professional skills from the actors of the educational process. But we also must 
admit that the changes that have already happened in the Germanic-Russian educational system that had existed in many countries of the Eastern Europe, distanced it from realization of the principle of fundamental preparation, and didn't make the process of training for students easier, but rather as technology, putting at the same time into the question the value of a humanitarian component which main task was to preserve the sociocultural cores of the culture of the country, in broadcasting of the cultural values.

\section{References}

Abramova, M. A. (2003) The ideas of humanity in culture and education of Yakutia. Yakutsk: YaNTs of the Siberian Branch of the Russian Academy of Science.

Abramova, M. A., Krasheninnikov, V.V., Libersk, X., Farnika, M. (2015) Broadcasting the culture and/or the development in activity: Germanic-Russian and Anglo-Saxon models of education. Philosophy of education. 2 (59), 37-45.

Abramova, M. A., Goncharova, G.S., Kostiuk, V.G. (2011). Sociocultural adaptation of youth of the North to the conditions of the modern transformations. Novosibirsk: Nonpareil

Ammosov, M.K. (1967) By means of Russians and workers and peasants. Yakutsk: Yakut book publishing house

Bernstein R.J. (1966) John Dewey. N.Y.: Washington Square Press.

Ivanova, L.T. (1968) Cultural revolution/The digest of documents and materials. Yakutsk: Bichik.

Kalashnikov, A.A. (2002) Yakutia. Chronicle. Facts. Events. 1632-1917. The state archive of the service of the Government of the Republic of Sakha (Yakutia). Yakutsk: Bichik.

Kelly, Donna Darling. (2004) Uncovering the History of Children's Drawing and Art. Greenwood Publishing Group, 2004.

National archive Republic Sakha (Yakutia). V. 828, №. 1, 267, P.17.

Parker, W. R. (1962) Education: Miltons ideas and ours, «College English».

Pesterev, V. I. (2005) History of Yakutia (1917 - 2003). Moscow: Omega-L.

Sadler, J.E. (1966) J.A. Comenius and the Concept of Universal Education. L.: Allen and Unwin.

Safronov, A.F. (edition) (2009) Academic science in Yakutia (1949-2009). Novosibirsk: Academic publishing house of "Geo"

Sorokin, P. A. (2000) Social and cultural dynamics. Researches of changes in big systems of art, truth, ethics, right and public relations. St. Petersburg.

Torgovkina, T.A. (edition) (2001) Yakutia: The XX century in a statistics mirror: Official Publishing / State. Lump. Russia. Federations of the statistics. Yakutsk: Sakhapoligrfizdat.

Zagvyazinsky, V. I. (2005) Educational strategy and educational policy. Science and education. 2, 3-8.

Zakharova, A.E. (2004) From the chronicle of the higher education in Yakutia. Yakutsk: Bichik. 
ISSN 2039-2117 (online)

ISSN 2039-9340 (print)
Mediterranean Journal of Social Sciences MCSER Publishing, Rome-Italy
Vol 7 No 6 November 2016 